\title{
Diffusion coefficients of lithium chloride and potassium chloride in hydrogel membranes derived from acrylamide
}

\author{
A.J.M. Valente ${ }^{\text {a }}$, A.Ya. Polishchuk ${ }^{\text {b }}$, V.M.M. Lobo ${ }^{\text {a,* }}$, G. Geuskens ${ }^{\text {c }}$

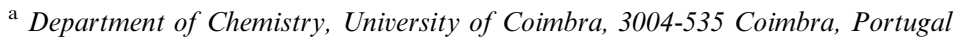 \\ ${ }^{\mathrm{b}}$ Institute of Biochemical Physics, Russian Academy of Sciences, 4 Kosygin Street, Moscow 117334, Russia \\ c Department of Macromolecular Chemistry, Free University of Brussels, Campus Plaine, CP206/1, B-1050 Brussels, Belgium
}

Received 23 April 2001; accepted 31 May 2001

\begin{abstract}
Diffusion of non-associated electrolytes (potassium chloride and lithium chloride) in concentrated aqueous solutions $\left(0.1-1.0 \mathrm{~mol} \mathrm{dm}^{-3}\right)$ has been studied in hydrogels derived from acrylamide and methyl methacrylate to study the mechanism of electrolyte transport. The preparation of two gels with different monomer ratio compositions resulted in obtaining membranes of substantially different hydrophilic character with polymer fractions of 0.3 and 0.5 .

Cukier hydrodynamic model was applied to explain the dependence of the diffusion coefficients of $\mathrm{KCl}$ and $\mathrm{LiCl}$ on the electrolyte concentration in hydrogel obtained experimentally. It was shown that the increase of the diffusion coefficients is accompanied with a decrease of the mean distance of approach of the ions. This can be explained by the formation of ion-pairs, resulting in a further contribution to diffusion once there is a decrease in the hydrodynamic resistance of the medium to the diffusing particles. Parameters, which characterise such a behaviour quantitatively, are different for different electrolytes and depend on water content in the gel. (c) 2001 Published by Elsevier Science Ltd.
\end{abstract}

Keywords: Diffusion coefficients; Hydrogels; Acrylamide; Methylmethacrylate; Water; Electrolytes

\section{Introduction}

Diffusion of molecules in polymer gels has been the subject of several studies [1]. The role of diffusion processes in many industrial applications of hydrogels and consequent need to control the diffusion and obtain the desirable diffusion characteristics accounts for the increasing interest in this area.

The hydrophilic character of acrylamide (AAm) hydrogels depends on the concentration of cross-linker [2]. However, the possibility of altering the material hydro-

\footnotetext{
* Corresponding author. Tel.: +351-239-828-403; fax: +351239-827-703.

E-mail address: vlobo@ci.uc.pt (V.M.M. Lobo).
}

philicity using this finding is severely limited. An alternative way for controlling the hydrophilic/hydrophobic balance in polyacrylamide-based hydrogels, is the design of co-polymers containing hydrophobic monomers. An investigation of the effect of a specific co-monomer, the methyl methacrylate (MMA), on the transport of nonassociated electrolytes $(\mathrm{KCl}$ and $\mathrm{LiCl})$ in AAm-based gels is the scope of this paper.

\section{Experimental}

\subsection{Reagents}

The chemicals are from the following sources: AAm and MMA from Riedel-de Häen; $N, N^{\prime}$-methylene-bisacrylamide (MBAAm) from Merck; sodium persulphate 
from Fluka AG; poly(vinyl alcohol) (PVA) of molecular weight of 13000-23000 from Aldrich Co.; lithium chloride and $\mathrm{KCl}$ from Riedel-de Häen (these electrolytes were further dried until constant weight at $110^{\circ} \mathrm{C}$ $(\mathrm{KCl})$ and $180^{\circ} \mathrm{C}(\mathrm{LiCl})$ [3]); 2-propanol from Riedelde Häen; tri-distilled water from our laboratory. All chemicals were of Pro-Analysis quality and used without further purification.

\subsection{Synthesis}

Free-radical aqueous co-polymerisation of AAm and MMA was performed [4] using MBAAm as the crosslinking agent. The ratio between monomers in the synthesised polymer membranes was altered varying the amount of MMA (in 2-propanol).

The pre-gel solutions were prepared using the following procedure: AAm solution $\left(2.5 \mathrm{~mol} \mathrm{dm}^{-3}\right)$ was added to MMA solution $\left(2.5 \mathrm{moldm}^{-3}\right)$ in a volume ratio of $4: 1$ and $3: 2$ for gels I and II, respectively. The initiator $\left(\mathrm{Na}_{2} \mathrm{~S}_{2} \mathrm{O}_{8}\right)$ and the cross-linker (MBAAm) were also added in the proportions of $1 \%(\mathrm{w} / \mathrm{v})$ and $5 \%(\mathrm{~mol} /$ mol), respectively. All the components were mixed to obtain homogeneous solutions. For gel II it was necessary to add PVA in the concentration of $0.05 \%-0.1 \%$ $(w / v)$ in order to increase the mechanical strength of the membrane.

The hydrogel membranes were produced polymerising the pre-gel solution (Table 1) inside two glass sheets separated by plastic rubber gasket. Spring clips were used to hold the glass sheets together. After this procedure, the mould was placed in an oven at $50^{\circ} \mathrm{C}$ for $2 \mathrm{~h}$. The hydrogel membrane was then removed from the mould, placed between two plastic sheets, and stored inside an exsiccator at nearly $100 \%$ humidity.

\subsection{Sorption isotherms}

The concentration of a specific electrolyte sorbed by the membrane $\left(C_{\mathrm{eq}}\right)$ was calculated by measuring the concentration of salt in the aqueous solution prior to $\left(c_{0}\right)$ and after $\left(c_{\infty}\right)$ the swelling experiments, using a conductivity instrument (YSI 3200), according to

$C_{\mathrm{eq}}=\left(c_{\infty}-c_{0}\right) V / V_{\mathrm{p}}$

Table 1

Composition of the pre-gel solutions

\begin{tabular}{lllll}
\hline Hydrogel & $\begin{array}{l}\text { AAm/ } \\
\mathrm{v} \%\end{array}$ & $\begin{array}{l}\text { MMA/ } \\
\mathrm{v} \%\end{array}$ & $\begin{array}{l}\text { MBAAm/ } \\
(\mathrm{mol} / \mathrm{mol} \%)\end{array}$ & $\begin{array}{l}\text { PVA/ } \\
(\mathrm{w} / \mathrm{v} \%)\end{array}$ \\
\hline I & 80 & 20 & 5 & - \\
II & 60 & 40 & 5 & $0.05-0.1$ \\
\hline
\end{tabular}

AAm: acrylamide; MMA: methylmethacrylate; MBAAm: $N, N^{\prime}$-methylene-bis-acrylamide; PVA: poly(vinyl alcohol). where $V$ and $V_{\mathrm{p}}$ are the volume of the aqueous solution and membrane sample, respectively.

The membranes previously in equilibrium with water were then immersed in the electrolyte solution for two weeks, without stirring, in order to guarantee the equilibrium.

The approach to equilibrium was controlled gravimetrically (Sartorius analytical balance, with a resolution of $0.1 \mathrm{mg}$ ). Each experiment was repeated at least three times and they were carried out at $25^{\circ} \mathrm{C}$.

\subsection{Permeability cell}

The same permeability cell was used to measure steady-state flux $(J)$ of electrolyte through hydrogel membranes, which was earlier designed and described in the references $[5,6]$. The cell consists of two compartments of $250 \mathrm{~mL}$ each, connected by two horizontal tubes of $14 \mathrm{~mm}$ diameter. The polymeric membrane, previously swollen in water up to the equilibrium, is sealed with silicone between these two tubes thus separating compartments, of which one is initially filled with electrolyte solution and the other with water. The electrolyte flux was monitored using a selective chloride electrode coupled with a pH meter Methrom 645, with a $0.1 \mathrm{mV}$ resolution. The temperature remained constant throughout the permeability experiments (thermostatic bath multistirrer 6 from Velp Scientifica) and the solutions were stirred at $\approx 220 \mathrm{rpm}$ in both cells.

The initial concentration of electrolyte solution is in the range $0.1-1.0 \mathrm{~mol} \mathrm{dm}^{-3}$. For each of these initial concentrations, the electrolyte concentration inside the membrane $\left(C_{\text {eq }}\right)$ was calculated. This is taken as the concentration at the interface between the membrane and electrolyte solution. Each $C_{\mathrm{eq}}$ value was simply found using results of sorption experiments. The integral diffusion coefficient of the electrolyte in a gel, $D_{\mathrm{F}}$, was then calculated from

$D_{\mathrm{F}}=J 1 / C_{\text {eq }}$

for different $c$ values.

\section{Results and discussion}

The interaction between electrolyte molecules and polymer groups (physical or chemical sorption, immobilisation, formation of complexes involving water, etc.) can be generally described in terms of Langmuir sorption. It can be assumed that the sorption parameters are different for AAm and MMA monomers. Thus, in general, sorption of an electrolyte can be described by equations

$C_{\mathrm{eq}}=\left[C_{\mathrm{L} 1} K_{\mathrm{L} 1} c /\left(1+K_{\mathrm{L} 1} c\right)\right]+\left[C_{\mathrm{L} 2} K_{\mathrm{L} 2} c /\left(1+K_{\mathrm{L} 2} c\right)\right]$ 
where $C_{\mathrm{L} 1}$ is the concentration of the electrolyte molecules that could be sorbed due to interaction with, say, AAm groups at saturation conditions, $K_{\mathrm{L} 1}$ is the corresponding equilibrium constant, $C_{\mathrm{L} 2}$ and $K_{\mathrm{L} 2}$ are parameters characterising electrolyte interaction with MMA.

Eq. (3) can be re-written in form

$$
C_{\text {eq }}=C_{\mathrm{L}} K_{\mathrm{L}} c /\left(1+K_{\mathrm{L}} c\right)
$$

where $C_{\mathrm{L}}=C_{\mathrm{L} 1} C_{\mathrm{L} 2} /\left(C_{\mathrm{L} 1}+C_{\mathrm{L} 2}\right), \quad K_{\mathrm{L}}=K_{\mathrm{L} 1} K_{\mathrm{L} 2}\left(C_{\mathrm{L} 1}+\right.$ $\left.C_{\mathrm{L} 2}\right) /\left(K_{\mathrm{L} 1} C_{\mathrm{L} 1}+K_{\mathrm{L} 2} C_{\mathrm{L} 2}\right)$ are effective (or average) parameters of an electrolyte sorption by co-polymer.

The isotherms of electrolyte sorption by two gels shown for $\mathrm{KCl}$ and $\mathrm{LiCl}$ in Figs. 1 and 2, respectively, confirm the Langmuir character of sorption.

The fitting parameters of the experimental data using Eq. (4) are presented in Table 2 showing $C_{\mathrm{L}}$ decrease and $K_{\mathrm{L}}$ increase with the increase of the concentration of MMA-groups in the co-polymer. It is quite reasonable that more hydrophobic MMA sorbs less amount of electrolyte from aqueous solution than $\mathrm{AAm}$, and

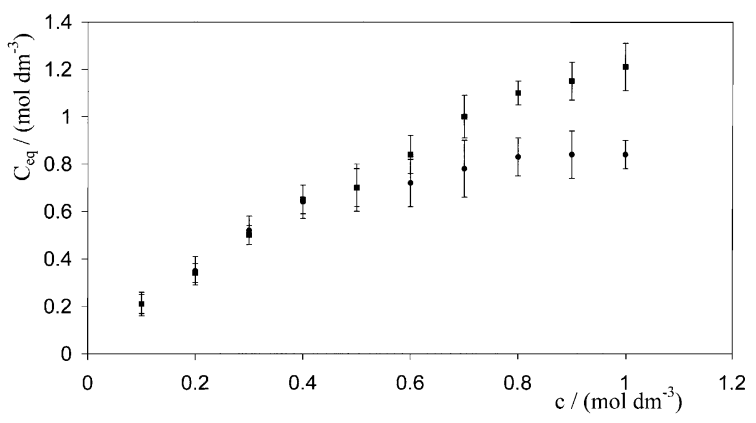

Fig. 1. Equilibrium sorption of $\mathrm{KCl}$ aqueous solutions by gel I (ם) and gel II (-), at $25^{\circ} \mathrm{C}$; $C_{\text {eq }}$ and $c$ are the concentration of electrolyte in the hydrogel and in water, respectively.

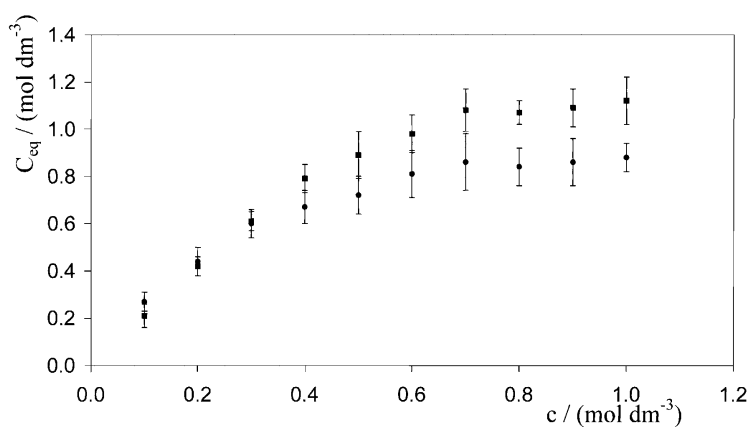

Fig. 2. Equilibrium sorption of $\mathrm{LiCl}$ aqueous solutions by gel I (ם) and gel II $(\bullet)$, at $25^{\circ} \mathrm{C}$; $C_{\text {eq }}$ and $c$ are the concentration of electrolyte in the hydrogel and in water, respectively.
Table 2

Langmuir's parameters computed from fitting Eq. (3) to the experimental data shown in sorption isotherms (Figs. 1 and 2)

\begin{tabular}{llllll}
\hline & \multicolumn{2}{l}{ KCl solutions } & & \multicolumn{2}{l}{ LiCl solutions } \\
\cline { 2 - 3 } \cline { 5 - 6 } & Gel I & Gel II & & Gel I & Gel II \\
\hline$C_{\mathrm{L}} / \mathrm{M}$ & 2.3 & 1.5 & & 3.2 & 1.3 \\
$K_{\mathrm{L}}$ & 0.5 & 1.7 & & 0.7 & 2.7 \\
\hline
\end{tabular}

therefore gel II is characterised by a lower $C_{\mathrm{L}}$ value than that of gel I. Furthermore, it is reported [7] that MMA should make the access of the electrolyte to the hydrated water molecules of the remaining polar groups of the gel more difficult, due to the steric hindrance. For this reason the contribution of AAm and MMA monomers in electrolyte sorption is not additive as it is proved by $C_{\mathrm{L}}$ data shown in Table 2.

An increase of the hydrophobic part of the network structure provokes a structure promotion to the water molecule [8]. In these circumstances the specific features of an electrolyte affect the stability of water molecules to a lesser degree. Consequently, the solubility of both electrolytes becomes similar as measured for $C_{\mathrm{L}}$ values of $\mathrm{KCl}$ and $\mathrm{LiCl}$ in gel II. This is not the case of gel I, where the predominant hydrophilic AAm groups are typically non-aqueous [8]. In this case water structure promotion is provoked by the lithium ions only, whereas potassium ions have the structure-breaker effect on the water molecules [9]. This can explain higher solubility of $\mathrm{LiCl}$ in gel I in comparison with that of $\mathrm{KCl}$.

Table 3 shows the integral diffusion coefficients $\left(D_{\mathrm{F}}\right)$ of $\mathrm{KCl}$ and $\mathrm{LiCl}$ in the gels I and II. The diffusion coefficients increase with the electrolyte concentration, $c$. Such an increase is more significant in the system gel I/ $\mathrm{KCl}$. For each gel, the variation of electrolyte diffusion coefficients is similar to that occurring in a free solution. For this reason we can assume that water-water and water-ion interactions play predominant role in the diffusion process. In other words, the higher diffusion coefficients of $\mathrm{KCl}$ in comparison with $\mathrm{LiCl}$ mean that hydrated ions are the predominant diffusing species in our gels. Therefore, to analyse $\mathrm{KCl}$ and $\mathrm{LiCl}$ diffusion in gels I and II quantitatively we should take into account water-ion (or water-electrolyte) and water-water interactions. Moreover, water-polymer interactions cannot be neglected because these hydrogels are characterised by a very inhomogeneous monomer density [10], resulting in the existence of polymer-solvent and pure solvent regions inside the matrix. On the other hand, a model of the process can be simplified by neglecting the polymer-solute interactions.

The hydrodynamic model developed by Cukier [11] satisfies the above conditions. It describes the dependence of diffusion coefficients of solutes $\left(D_{\mathrm{g}}\right)$ on the polymer volume fraction $(\varphi)$ by 
Table 3

Integral diffusion coefficients $\left(D_{\mathrm{F}}\right)$ of $\mathrm{KCl}$ and $\mathrm{LiCl}$ in poly(acrylamide-co-methyl methacrylate) membranes, at $25^{\circ} \mathrm{C}$

\begin{tabular}{|c|c|c|c|c|}
\hline \multirow[t]{2}{*}{$c /\left(\mathrm{mol} \mathrm{dm}^{-3}\right)$} & \multicolumn{4}{|c|}{$D_{\mathrm{F}}( \pm s) /\left(10^{-10} \mathrm{~m}^{2} \mathrm{~s}^{-1}\right)$} \\
\hline & $\mathrm{Gel} \mathrm{I} / \mathrm{KCl}$ & Gel II/KCl & $\mathrm{Gel} \mathrm{I} / \mathrm{LiCl}$ & Gel II/LiCl \\
\hline 0.1 & $4.57( \pm 0.41)$ & $1.77( \pm 0.09)$ & $3.14( \pm 0.18)$ & $1.41( \pm 0.08)$ \\
\hline 0.2 & $4.82( \pm 0.22)$ & $1.89( \pm 0.06)$ & $3.25( \pm 0.22)$ & $1.52( \pm 0.05)$ \\
\hline 0.3 & $5.40( \pm 0.16)$ & $2.02( \pm 0.04)$ & $3.44( \pm 0.23)$ & $1.60( \pm 0.10)$ \\
\hline 0.4 & $5.45( \pm 0.23)$ & $2.25( \pm 0.08)$ & $3.58( \pm 0.18)$ & $1.67( \pm 0.09)$ \\
\hline 0.5 & $5.50( \pm 0.31)$ & $2.86( \pm 0.06)$ & $3.71( \pm 0.30)$ & $1.88( \pm 0.08)$ \\
\hline 0.6 & $5.76( \pm 0.39)$ & $3.01( \pm 0.04)$ & $3.96( \pm 0.4)$ & $1.99( \pm 0.09)$ \\
\hline 0.7 & $5.88( \pm 0.22)$ & $3.32( \pm 0.07)$ & $4.02( \pm 0.09)$ & $2.28( \pm 0.06)$ \\
\hline 0.8 & $6.11( \pm 0.18)$ & $3.49( \pm 0.07)$ & $4.30( \pm 0.12)$ & $2.46( \pm 0.08)$ \\
\hline 0.9 & $6.48( \pm 0.08)$ & $3.55( \pm 0.04)$ & $4.75( \pm 0.41)$ & $2.78( \pm 0.09)$ \\
\hline 1.0 & $6.86( \pm 0.10)$ & $3.69( \pm 0.08)$ & $5.00( \pm 0.35)$ & $2.95( \pm 0.08)$ \\
\hline
\end{tabular}

$s$ : standard deviation of the mean.

Table 4

Degree of swelling $(Q \pm s)$ for polyacrylamide-based hydrogels in aqueous $\mathrm{KCl}$ and $\mathrm{LiCl}$ solutions at $25^{\circ} \mathrm{C}$ and $\varphi$ (Eq. (6))

\begin{tabular}{lllll}
\hline$c /\left(\mathrm{mol} \mathrm{dm}^{-3}\right)$ & $\mathrm{KCl}$ & $\mathrm{LiCl}$ & \\
\hline 0 & $5.12( \pm 0.01)$ & $3.00( \pm 0.03)$ & $5.24( \pm 0.04)$ & $3.12( \pm 0.02)$ \\
0.1 & 5.19 & $3.00( \pm 0.01)$ & $5.31( \pm 0.03)$ & $3.12( \pm 0.01)$ \\
0.3 & 5.27 & $3.01( \pm 0.01)$ & $5.36( \pm 0.01)$ & 3.13 \\
0.5 & 5.33 & $3.00( \pm 0.01)$ & 5.38 & 3.12 \\
0.7 & $5.35( \pm 0.01)$ & $2.98( \pm 0.01)$ & $5.40( \pm 0.01)$ & 3.11 \\
1 & $5.37( \pm 0.01)$ & $2.97( \pm 0.01)$ & 5.41 & 3.11 \\
$\varphi$ & 0.30 & 0.48 & 0.29 & 0.47 \\
\hline
\end{tabular}

$s$ : standard deviation of the mean.

$D_{\mathrm{g}}=D_{0} \exp \left(-k_{\mathrm{c}} r_{\mathrm{s}} \varphi^{0.75}\right)$

where $D_{0}$ is the diffusion coefficient of the electrolyte in aqueous solution [12,13], $k_{\mathrm{c}}$ is a constant parameter characterising specific polymer-solvent system, and $r_{\mathrm{s}}$ is the radius of the solute. Since the ions of different charge diffuse with the same velocity of the system (due to electroneutrality), $r_{\mathrm{s}}$ corresponds to a mean distance of approach of the ions. The polymer volume fractions of our systems (Table 4) were calculated using [10]

$\varphi=\left\{1+\left[(Q-1) \rho_{\mathrm{p}} / d\right]\right\}^{-1}$

assuming that all sorbed electrolyte has a density, $d$, similar to that in aqueous solutions [14]. The polymer densities, $\rho_{\mathrm{p}}$, of gels I and II are $0.55( \pm 0.03)$ and 0.53 $( \pm 0.01) \mathrm{g} \mathrm{cm}^{-3}$, respectively. These values were calculated assuming water density in the gels equal to 1 $\mathrm{g} \mathrm{cm}^{-3}$. The swelling degrees of the gel, $Q$ is mass of hydrogel/mass of xerogel, are shown in Table 4 as they vary with electrolyte concentration.

Since polymer volume fraction does not vary with $C_{\text {eq }}$, the increase of $D_{\mathrm{F}}$ with the increase of electrolyte concentration should have another explanation. Figs. 3 and 4 show how the factor $\left(k_{\mathrm{c}} r_{\mathrm{s}}\right)$ changes with the $\mathrm{KCl}$ and $\mathrm{LiCl}$ concentration inside matrices, $C_{\text {eq }}$, respectively. The $\left(k_{\mathrm{c}} r_{\mathrm{s}}\right)$ factor was calculated using $D_{\mathrm{g}}=D_{\mathrm{F}}$. These

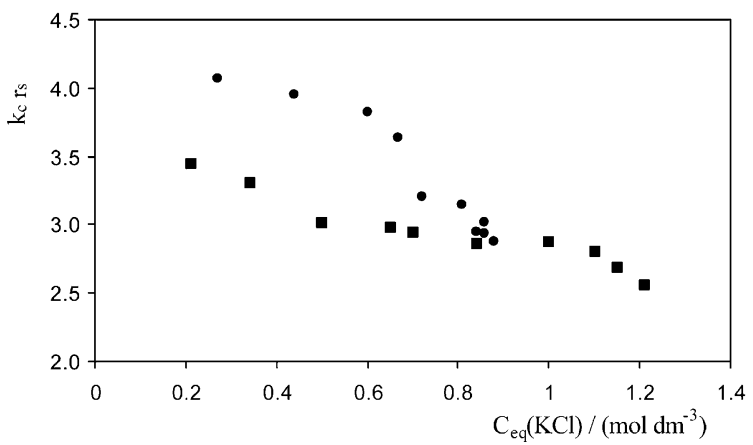

Fig. 3. Dependence of $k_{\mathrm{c}} r_{\mathrm{s}}$ on the concentration of the $\mathrm{KCl}$ aqueous solution in the gel I (ם) and in the gel II

figures show the decrease of $\left(k_{\mathrm{c}} r_{\mathrm{s}}\right)$ with an increase of $C_{\text {eq }}$, and this should be due to $r_{\mathrm{s}}$ decrease because $k_{\mathrm{c}}$ is a constant for each gel/electrolyte system. Such a decrease can be interpreted as a close position of the ions with consequent ion-pair formation. This form of electrolyte is characterised by less resistance to motion through the liquid than it would be in the case of two separate ions. Consequently, ion-pairs make a contribution to an electrolyte flux increasing the apparent diffusion coefficient $D_{\mathrm{F}}$. Such an assumption is in agreement with experi- 


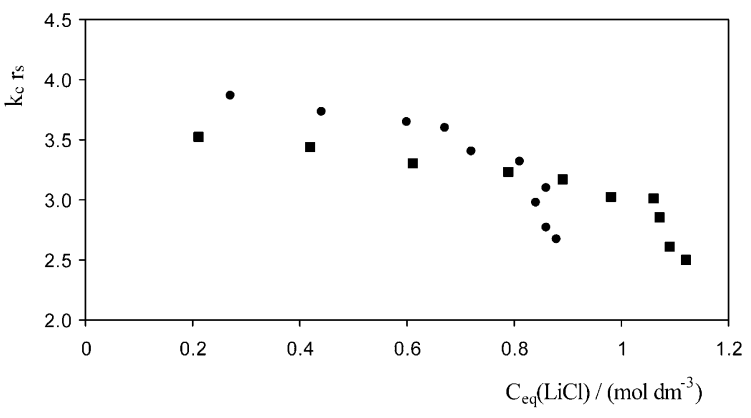

Fig. 4. Dependence of $k_{\mathrm{c}} r_{\mathrm{s}}$ on the concentration of the $\mathrm{LiCl}$ aqueous solution in the gel I (ם) and in the gel II

mental results reported by Zaikov et al. [15, pp.101, 102].

More significant variation of $r_{\mathrm{s}}$ with concentration, which is observed for gel II, is a consequence of the decrease of the water content available as diffusing media. The later results in an easier approach of the counter-ions to each other.

The values of $k_{\mathrm{c}}$, can be estimated for all systems using Eq. (5) and data reported in Figs. 3 and 4 if we extrapolate the fitting lines to $C_{\mathrm{eq}}=0$. If concentration is relatively low (close to infinitesimal values), the ions diffuse as single entities and their radius, $r$, can be calculated directly from the Stokes-Einstein equation

$r=\left(k_{\mathrm{B}} T\right) /\left(6 \pi \eta D^{0}\right)$

where $k_{\mathrm{B}}$ is the Boltzmann's constant, $T$ is the temperature and $\eta$ is the water viscosity at that temperature ( $T=298 \mathrm{~K}$ in our case). The Nernst limiting diffusion coefficients, $D^{0}$, of $\mathrm{KCl}$ and $\mathrm{LiCl}$ were calculated from the limiting ionic conductivities [16] and are $1.994 \times$ $10^{-9}$ and $1.367 \times 10^{-9} \mathrm{~m}^{2} \mathrm{~s}^{-1}$, respectively. Introducing experimental data into Eq. (7) we find the radii of $\mathrm{KCl}$ and $\mathrm{LiCl}$ as 1.229 and $1.793 \AA$, respectively.

The calculated values of $k_{\mathrm{c}}$ are reported in Table 5 showing: (a) the different effect of $\mathrm{KCl}$ and $\mathrm{LiCl}$ on the polymer-water interactions (this is in close agreement

Table 5

Estimated values of $k_{\mathrm{c}}$ for the polyacrylamide/electrolyte/water systems, using the radius of the electrolyte $(r)$ and the mean distance of approach of the ions $(a)$ from Ref. [16]

\begin{tabular}{|c|c|c|c|c|c|}
\hline & $r / \AA$ & $a / \AA$ & $\begin{array}{l}r_{\mathrm{s}} k_{\mathrm{c}} \\
\left(C_{\mathrm{eq}}=0\right)\end{array}$ & $\begin{array}{l}k_{\mathrm{c}} \\
\left(r_{\mathrm{s}}=r\right)\end{array}$ & $\begin{array}{l}k_{\mathrm{c}} \\
\left(r_{\mathrm{s}}=a\right)\end{array}$ \\
\hline $\begin{array}{l}\text { Gel I/ } \\
\mathrm{KCl}\end{array}$ & 1.229 & 3.63 & 3.79 & 3.1 & 1.0 \\
\hline $\begin{array}{l}\text { Gel II/ } \\
\mathrm{KCl}\end{array}$ & & & 4.22 & 3.4 & 1.2 \\
\hline $\begin{array}{l}\text { Gel I/ } \\
\mathrm{LiCl}\end{array}$ & 1.793 & 4.32 & 3.64 & 2.0 & 0.84 \\
\hline $\begin{array}{l}\text { Gel II/ } \\
\mathrm{LiCl}\end{array}$ & & & 4.04 & 2.2 & 0.93 \\
\hline
\end{tabular}

with the possible effect of the ions on the water molecule structure); (b) that the values of $k_{\mathrm{c}}$ obtained using the radius of the electrolyte $\left(r_{\mathrm{s}}\right)$ are three, two times higher than those reported by Amsden [17] for polyacrylamide systems. This means that when we are talking about strong electrolytes we must take into account the mean distance of approach instead of the solute radius, which is meaningless in this case. Substituting the solute radius computed using Eq. (7), by the mean distance of approach of the ions, $a$, in dilute solutions (3.63 and $4.32 \AA$ [16] for $\mathrm{KCl}$ and $\mathrm{LiCl}$ respectively), we find the values of $k_{\mathrm{c}}$ (Table 5) which agree with those reported in literature [17].

The analysis of $k_{\mathrm{c}}$ values shows that: (i) the dependence of $D_{\mathrm{F}}$ on the "solute radius" is less affected by the polymer-water interactions in the systems containing $\mathrm{LiCl}$; (ii) as water concentration decreases inside the matrix the probability of ion-pairs formation increases, and, consequently, the diffusion coefficients are more variable within a small range of concentration.

\section{Conclusions}

A co-polymerisation of AAm hydrogels with MMA resulted in interesting findings in comparison with an earlier attempt to alter hydrophilic character of AAm gels by cross-linking [18]. The osmotic effect of salts, which was observed therein [18], is nearly cancelled by introduction of hydrophobic monomer. Furthermore, the diffusion coefficients of $\mathrm{KCl}$ and $\mathrm{LiCl}$ in co-polymers depend on a wider set of interactions. The most relevant one is the ion-ion interaction. An application of $\mathrm{Cu}-$ kier's model [11] made possible to find that the increase of the diffusion coefficients are due to a decrease in the mean distance of approach of the ions. This can lead to the formation of ion-pairs and their contribution to the total flux of an electrolyte. An increase of MMA content in the polymer chain results in stronger dependence of effective diffusion coefficient of an electrolyte on the apparent radius of the solute. Thus, the synthesised gels can be used to induce ion-pair formation of strong electrolytes in a concentration range where, in free solutions, ion-pairs do not exist.

\section{Acknowledgements}

Financial support from PRAXIS/XXI is gratefully acknowledged.

\section{References}

[1] Muhr AM, Blanshard JMV. Diffusion in gels. Polymer 1982;23:1012-26. 
[2] Baker JP, Hong LH, Blanch HW, Prausnitz JM. Effect of initial total monomer concentration on the swelling behavior of cationic acrylamide-based hydrogels. Macromolecules 1994;27:1446-54.

[3] Duval C. Inorganic thermogravimetric analysis. New York: Elsevier; 1953.

[4] Tobita H, Hamielec AE. Crosslinking kinetics in polyacrylamide networks. Polymer 1991;31:1546-52.

[5] Valente AJM, Polishchuk AYa, Lobo VMM, Burrows HD. Transport properties of concentrated aqueous sodium dodecyl sulfate solutions in polymer membranes derived from cellulose esters. Langmuir 2000;16:6475-9.

[6] Polishchuk AYa, Valente AJM, Camino G, Luda MP, Madyuskin NN, Lobo VMM, Zaikov GE, Revellino M. Diffusion of electrolytes in hydrolysable glassy polymers. Acetic acid in polyvinyl acetate, polyvinyl alcohol and polyesters. Polym-Plast Technol Engng, in press.

[7] Corkhill PH, Jolly AM, Ng CO, Tighe BJ. Synthetic hydrogels: 1. Hydroxyalkyl acrylate and methacrylate copolymers - water binding studies. Polymer 1987;28: 1758-66.

[8] Frank HS, Frank F. Structural approach to the solvent power of water for hydrocarbons; Urea as a structure breaker. J Chem Phys 1968;48:4746-57.
[9] Samoilov OYa. A new approach to the study of hydration of ions in aqueous solutions. Discuss Faraday Soc 1957;24:141-6.

[10] Naghash HJ, Okay O. Formation and structure of polyacrylamide gels. J Appl Polym Sci 1996;60:971-9.

[11] Cukier RI. Diffusion of browninan spheres in semidilute polymer solutions. Macromolecules 1984;17:252-5.

[12] Lobo VMM, Valente AJM. The open-ended capillary cell. A method to measure a large range of concentrations of electrolyte aqueous solutions. Port Electrochim Acta 1996;14:133-7.

[13] Valente AJM, Lobo VMM. Mutual diffusion coefficients of aqueous lithium chloride in solutions at $25^{\circ} \mathrm{C}$. Port Electrochim Acta 2000;18:159-65.

[14] Lobo VMM. Handbook of electrolyte solutions. Amsterdam: Elsevier; 1990.

[15] Zaikov GE, Iordanskii AL, Markin VS. Diffusion of electrolytes in polymers. Utrecht: VSP; 1988.

[16] Robinson RA, Stokes RH. Electrolyte solutions. London: Butterworths; 1959.

[17] Amsden B. Solute diffusion within hydrogels. Mechanisms and models. Macromolecules 1998;31:8382-95.

[18] Lobo VMM, Valente AJM, Polishchuk AYa, Geukens G. Transport of non-associated electrolytes in acrylamide hydrogels. J Mol Liquids, in press. 